\title{
CORRELATION BETWEEN ORGANIZATION CULTURE WITH ORGANIZATION COMMITMENT ON EMPLOYEE AT PT. YODYA KARYA (PERSERO) JAKATA TIMUR
}

\author{
Muhammad Rahmansyah \\ Fakultas Ekonomi, Universitas Negeri Jakarta \\ rahmansyah@gmail.com \\ Umi Widyastuti \\ Fakultas Ekonomi, Universitas Negeri Jakarta \\ Umiwidyastuti_feunj@unj.ac.id \\ Darma Rika Swaramarinda \\ Fakultas Ekonomi, Universitas Negeri Jakarta \\ darmarika@gmail.com
}

\begin{abstract}
The purpose of this research is to detect correlation between organization culture with organization commitment on Employee at PT. Yodya Karya. The research is done during for two months since May until June 2014. The method of research is survey method with correlation approach. The population research was employee in PT. Yodya Karya center board with total 57 employee, and 48 employees for sampling and used probability random sampling. Instrument that used to get variable data $X$ (Organization Culture) and variable data $Y$ measured by questionnaire using Likert scale. The analysis test by finding regression equation, that is $\hat{Y}$ $=45,47+0,29 X$. Analysis rules test that is test normalitas while analysis rules test that is test normalitas regression estimation error $Y$ on $X$ with test Liliefors got Litung $(0,1202)<$ Ltabel $(0,1278)$ matters this means sample comes from population normal distribution. Significancy test and regression linearity by using analysis table varians (Anava) got regression similiarity Fhitung $(8,67)>$ Ftabel $(4,05)$ that declare regression very mean with regression linearity test that produce Fhitung $(0,91)<$ Ftabel $(2,04)$ that show the regression model that used linear. Correlation coefficient hypothesis test is done with formula product moment produce rhitung $=0,401$. Significancy test with thitung $(2,97)>$ ttabel $(1,68)$. Because thitung $>$ ttabel, from watchfullness result so researcher can conclude that found connection significant between organization culture with organization commitment on employee PT. Yodya Karya. Determination coeficient test produce KD as big
\end{abstract}


as $16,1 \%$. So can be taken conclusion found which are positive connection and significant between organization culture and organization commitment.

Keywords : Organization Culture, Organization Commitment

\section{PENDAHULUAN}

Karyawan yang kurang berkomitmen terhadap organisasi tentu tidak akan memberikan kontribusi yang maksimal bagi perusahaan. Karyawan tersebut tidak akan bekerja dengan sungguh-sungguh untuk membantu perusahaan mencapai tujuannya. Selain itu, karyawan yang komitmen organisasinya rendah tidak akan memberikan dedikasi yang tinggi kepada pekerjaannya. Hal ini akan berdampak kepada minimnya sumbangsih yang diberikan karyawan kepada perusahaan. Oleh karena itu, penting bagi setiap perusahaan untuk selalu berusaha menjaga dan meningkatkan komitmen organisasi karyawannya.

Faktor penting yang dapat mempengaruhi komitmen organisasi karyawan adalah budaya organisasi. Pemahaman karyawan mengenai budaya organisasi akan membentuk konsep kerja karyawan. Selain itu, pemahaman terhadap budaya organisasi membuat karyawan dapat memahami dan mengenal tujuan organisasi serta dapat beradaptasi dengan lingkungan kerja di perusahaan. Budaya organisasi yang kuat juga akan meningkatkan komitmen karyawan untuk menjalankan nilainilai yang terkandung di dalamnya. Hal tersebut secara tidak langsung akan meningkatkan komitmen organisasi dan loyalitas karyawan terhadap perusahaan.

Pada kenyataannya, masih banyak karyawan yang kurang memahami budaya organisasi perusahaannya. Seperti yang terjadi di PT. Yodya Karya, sosialisasi dan pemahaman karyawan terhadap budaya organisasi perusahaan masih rendah. Hal ini dapat dilihat dari kurangnya penerapan nilai disiplin dalam diri karyawan. Selain itu, sosialisasi budaya PRESISI (Profesional, Realibility, Empowerment, Sinergy, Integrity, Sustainability serta Inovation) yang dimiliki perusahaan minim dilakukan, sehingga masih banyak karyawan yang tidak mengetahui seperti apa budaya organisasi perusahaan tersebut. Akibatnya, komitmen organisasi karyawan dalam menjalankan nilai-nilai budaya organisasi yang terkandung didalamnya belum maksimal diterapkan oleh karyawan dalam bekerja.

Dari hal-hal yang telah 
dikemukakan di atas menunjukkan bahwa budaya organisasi di sebuah perusahaan dapat mempengaruhi komitmen organisasi karyawan. Budaya organisasi yang kuat bila ditanamkan dengan baik dalam diri karyawan dapat meningkatkan komitmen organisasi karyawan serta konsistensi perilaku karyawan dalam melaksanakannya. Hal tersebutlah yang membuat peneliti tertarik untuk melakukan penelitian mengenai hubungan budaya organisasi dengan komitmen organisasi pada karyawan PT. Yodya Karya.

\section{PERUMUSAN MASALAH}

Berdasarkan pembatasan masalah di atas, maka permasalahan dalam penelitian ini dapat dirumuskan menjadi "Apakah terdapat hubungan antara budaya organisasi dengan komitmen organisasi karyawan?"

\section{Komitmen Organisasi}

Menurut Kaswan (Kaswan, 2012)menjelaskan komitmen organisasi merupakan "ukuran kesediaan karyawan bertahan dengan sebuah perusahaan di waktu yang akan datang". Hampir sama dengan pendapat tersebut, Jason (Colquit, 2011) menyatakan "Organizational co-mmitment is defined as the desire on the part of an employee to remain a member of the organization (Komitmen organisasi didefinisikan sebagai bagian keinginan dari karyawan untuk tetap menjadi anggota organisasi)".

Hal senada juga diungkapkan Robbins (Robbins, 2009)mengungkapkan

"Organizational commitment is the degree to which an employee identifies with a particular organization and its goals and wishes to remain membership in that organization (Komitmen organisasi adalah sejauh mana seorang karyawan mengidentifikasi organisasi tertentu dan tujuannya serta berharap tetap menjadi anggota organisasi tersebut)". Jadi, komitmen organisasi dapat didefinisikan sebagai keinginan karyawan untuk bertahan dan tetap menjadi anggota organisasi. Karyawan yang memiliki komitmen tidak akan berpikir untuk pindah atau bahkan keluar dari organisasi tempatnya bekerja.

Kemudian, Robbins dan Judge dalam Danang (Sunyoto, 2011)menyatakan bahwa komitmen organisasi terdiri dari tiga dimensi:

a.Komitmen afektif, yaitu perasaan emosional untuk organisasi dan keyakinan dalam nilai-nilainya.

b.Komitmen berkelanjutan (continuance commitment), yaitu nilai ekonomi yang dirasakan jika tetap bertahan di dalam organisasi dibandingkan jika meninggalkan organisasi tersebut. 
c. Komitmen normatif, yaitu kewajiban untuk tetap bertahan dalam organisasi karena alasanalasan etis dan moral.

Hal senada dikemukakan Summers dan Acito dalam Edy Sutrisno (Sunyoto D. , 2012)yang menjelas-kan bahwa terdapat tiga aspek komitmen organisasi, yaitu:

a. Continuance commitment, dapat didefinisikan sebagai keterikatan anggota secara psikologis pada organisasi karena biaya yang dia tanggung sebagai konsekuensi keluar organisasi.

b. Normative commitment, adalah keterikatan anggota secara psikologis dengan organisasi karena kewajiban moral untuk memelihara hubungan dengan organisasi.

c. Affective commitment, adalah tingkat keterikatan secara psikologis dengan organisasi berdasarkan seberapa baik perasaan mengenai organisasi

Dari pendapat di atas dapat dilihat bahwa terdapat tiga jenis komitmen organisasi. Pendapat tersebut diperkuat oleh Meyer dan Allen dalam Luthans (Luthans, 2006)mengemukakan tiga dimensi komitmen organisasi:

1. Komitmen afektif, adalah keterikatan emosional karyawan, identifikasi, dan keterlibatan dalam organisasi.

2. Komitmen kelanjutan, adalah komitmen berdasarkan keru- gian yang berhubungan dengan keluarnya karyawan dari organisasi

3. Komitmen normatif, adalah perasaan wajib untuk tetap berada dalam organisasi karena memang harus begitu; tindakan tersebut merupakan hal benar yang harus dilakukan

Hal tersebut juga didukung Mowday yang dikutip Sopiah (Sopiah, 2008)yang menyatakan ada tiga aspek komitmen antara lain :

a. Affective commitment, yang berkaitan dengan adanya keinginan untuk terikat pada organisasi. Individu menetap dalam organisasi karena keinginan sendiri. Kunci dari komitmen ini adalah want to

b. Continuance commitment, adalah suatu komitmen yangdidasarkan akan kebutuhan rasional. Dengan kata lain, komitmen ini terbentuk atas dasar untung rugi, dipertimbangkan atas apa yang harus dikorbankan bila akan menetap pada suatu organisasi. Kunci dari komitmen ini adalah kebutuhan untuk bertahan (need to)

c. Normative Commitment, adalah komitmen yang didasarkan pada norma yang ada dalam diri karyawan, berisi keyakinan individu akan tanggung jawab terhadap organisasi. Ia 


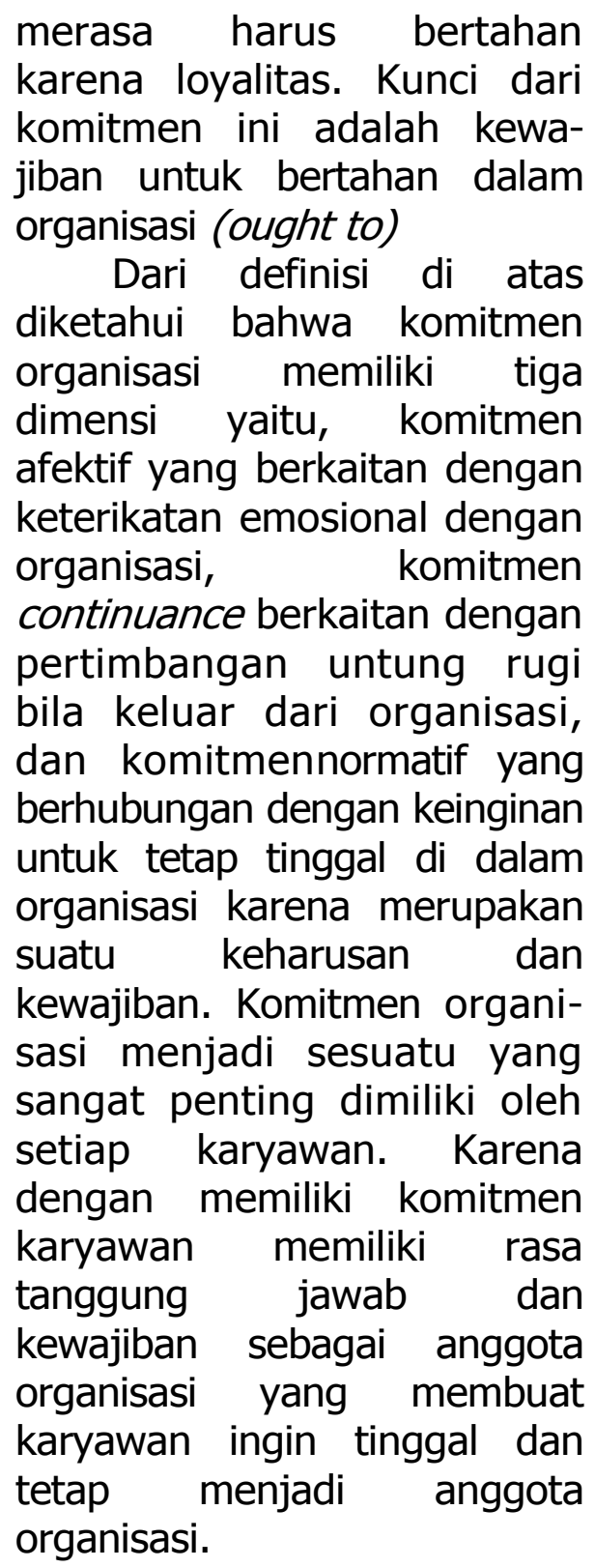

Dari kajian teori di atas dapat ditarik kesimpulan bahwa komitmen organisasi merupakan sikap bangga yang ditunjukkan karyawan sebagai bagian dari organisasi dengan memberikan kontribusi bagi kemajuan dan perkembangan organisasi yang mencerminkan affective commitment (komitmen afektif), continuance commitment(komitmen

berkelanjutan), dan normative commitment (komitmen normatif).

Menurut Robbins dalam Edy Sutrisno (Sunyoto D. , 2012), "budaya organisasi merupakan sistem nilai bersama dalam suatu organisasi yang menentukan tingkatan bagai-mana para karyawan melakukan kegiatan untuk mencapai tujuan organisasi". Budaya organisasi mengandung nilai yang diakui secara bersama-sama oleh anggota organisasi yang digunakan oleh para anggotanya sebagai landasan dalam bekerja dan beraktifitas guna mencapai tujuan dari organisasi tempat mereka bekerja.

Lain halnya dengan Klikman dalam Edy Sutrisno (Sunyoto D. , 2012)yang mengatakan bahwa "budaya organisasi merupakan jiwa organisasi dan jiwa para anggota organisasi". Budaya organisasi dipandang sebagai jiwa para anggotanya. Hal ini disebabkan karena budaya tersebut tumbuh dan berkembang di dalam organisasi yang dihayati oleh setiap anggota di dalamnya.

Danang Sunyoto dan Burhanudin dalam Danang (Sunyoto D. d., 2011)menjelaskan mengenai karakteristik budaya organisasi yang terdiri dari: 
a. Inovasi dan keberanian mengambil resiko. Sejauh mana karyawan didorong agar bersikap inovatif dan berani mengambil resiko.

b. Perhatian pada hal-hal rinci/detail. Sejauh mana karyawan diharapkan menjalankan kecermatan/precision analisis dan perhatian pada hal-hal detail.

c. Orientasi hasil. Sejauh mana pihak manajamen lebih fokus pada hasil daripada fokus pada tekhnik atau proses yang digunakan untuk mencapai hasil tersebut.

d. Orientasi orang. Sejauh mana keputusan-keputusan manajemen mempertimbangkan efek dari hasil tersebut terhadap orangorang yang ada di dalam organisasi.

e. Orientasi team Sejauh mana kegiatan-kegiatan kerja diorganisasi pada team daripada individu-individu.

f. Keagresifan/aggressiveness.

Sejuh mana orang bersikap agresif dan kompetititf daripada santai.

g. Stabilitas.Sejauhmanake-

giatan-kegiatan organisasimenekankan dipertahankannya status quo sebagai lawan dari pertumbuhan

Senada dengan pendapat di atas, Robbins dalam Umam (Umam, 2012)memberikan tujuh karakteristik budaya organisasi, yaitu:

a. Inovasi dan keberanian mengambil resiko

b. Pehatian terhadap detail.

c. Berorientasi pada hasil.

d. Berorientasi kepada manusia.

e. Berorientasi pada tim.

f. Agresivitas.

g. Stabilitas

Kedua pendapat tersebut juga didukung oleh Veithzal Rivai(Rivai, 2010)yang menjelaskan tujuh karakteristik budaya organisasi, yaitu:

a. Inovasi dan pengambilan resiko, sejauh mana para karyawan

didorong untuk inovatif dan mengambil resiko.

b. Perhatian, sejauh mana karyawan diharapkan meperhatikan presisi (kecermatan dan analisis).

c. Orientasi hasil, sejauh mana manajamen memfokuskan padahasil, bukan pada tekhnik dan proses.

d. Orientasi orang, sejauh mana keputusan manajemen memperhitungkan efek keberhasilan orang-orang di dalam organisasi.

e. Orientasi tim, sejauh mana kegiatan kerja diorganisasikankepada tim, bukannya individu-individu.

f. Keagresifan, sejauh mana 
orang-orang itu agresif (kreatif) dankompetitif.

g. Kemantapan, sejauh mana kegiatan organisasi menekankan dipertahankannya status quo.

Dari beberapa pengertian budaya organisasi yang dikemukakan para ahli di atas, dapat ditarik kesimpulan bahwa budaya organisasi merupakan nilai, sikap, dan norma yang disepakati bersama dan mengarahkan perilaku anggota organisasi yang mencerminkan inovasi dan pengambilan resiko, perhatian pada detail, orientasi hasil, orientasi pada orang, orientasi tim, keagresifan, dan stabilitas.

\section{METODE PENELITAN}

Metode penelitian yang digunakan dalam penelitian ini adalah metode survey dengan pendekatan korelasional serta menggunakan kuisioner dalam pengumpulan datanya. Metode tersebut dipilih karena sesuai dengan tujuan penelitian yang ingin dicapai, yaitu untuk mengetahui hubungan budaya organisasi terhadap komitmen organisasi.

\section{Populasi dan Sampling}

Menurut Sugiyono (Sugiyono, 2011), "Populasi adalah wilayah generalisasi yang terdiri atas: obyek/subyek yang mempunyai kualitas dan karakteristik tertentu yang ditetapkan oleh peneliti untuk dipelajari dan kemudian ditarik kesimpulannya". Populasi penelitian ini adalah karyawan kantor pusat PT. Yodya Karya yang berjumlah 57 karyawan.Sampel penelitian yang diambil sebanyak 48 karyawan sesuai dengan tabel Isaac dan Michael dengan tingkat kesalahan sebesar 5\%. Sampel ini dipilih karena karyawan tersebut dinilai mengetahui dengan baik budaya organisasi perusahaan sehingga mempermudah peneliti dalam melakukan penelitian.

Teknik pengambilan sampel yang digunakan dalam penelitian ini adalah teknik proporsional random sampling (proportional random sample technique).

\section{Persamaan Regresi}

Analisis regresi linear sederhana terhadap pasangan data penelitian antara budaya organisasi dengan komitmen organisasi karya-wan menghasilkan koefisien arah regresi sebesar 0,29 dan menghasilkan konstanta sebesar 45,47 dengan demikian bentuk hubungan antara variabel budaya organisasi dengan komitmen organisasi karyawan memiliki persamaan regresi $\hat{Y}=45,47+$ 0,29X.Persamaan regresi tersebut menunjukkan bahwa setiap kenaikan satu skor budaya organisasi (X) akan mengakibatkan peningkatan komit-men 
organisasi ( $(Y)$ sebesar 0,29 skor pada konstanta 45,47.

\section{Uji Normalitas}

Hasil perhitungan uji Liliefors menyimpulkan bahwa taksiran regresi $Y$ atas $X$ berdistribusi normal. Hal ini dapat dibuktikan dengan hasil perhitungan Lo = 0,1202 sedangkan $L t=0,1278$. Ini berarti Lo < Lt artinya data berdistribusi normal.

\section{Uji Koefisien Korelasi}

Hasil perhitungan koefisien korelasi antara budaya organisasi dengan komitmen organisasi menghasilkan $\mathrm{rxy}=0,401$. Ini menunjukkan rxy $>0$ sehingga dapat disimpulkan bahwa terdapat hubungan yang positif antara budaya organisasi dengan komitmen organisasi.

\section{Uji Koefisien Determinasi}

Uji koefisien determinasi digunakan untuk mengetahui seberapa besar hubungan variabel $X$ (budaya organisasi) dengan variabel $Y$ (komitmen organisasi). Dari hasil hitung, diperoleh rxy sebesar $\left(0,401^{2}\right)=0,1608$. Dari perhitungan tersebut dapat disimpulkan bahwa budaya organisasi mempengaruhi komitmen organisasi sebesar $16,08 \%$ dan sisanya dipengaruhi oleh faktor lain yang tidak diteliti dalam penelitian ini.

\section{HASIL PENELITIAN DAN PEMBAHASAN}

Berdasarkan penelitian yang telah dilakukan diperoleh model persamaan regresi $\hat{Y}=$ $45,47+0.29 X$ artinya bahwa kenaikan satu skor variabel $X$ (budaya organisasi) akan meningkatkan variabel $Y$ (komitmen organisasi) sebesar 0.29 pada konstanta 45,47 .

Lalu diketahui nilai koefisien korelasi rxy sebesar 0,401 dan thitung sebesar 2,97 > ttabel sebesar 1.68 sehingga dapat disimpulkan bahwa terdapat hubungan positif antara budaya organisasi dengan komitmen organisasi, artinya semakin kuat budaya organisasi sebuah perusahaan maka semakin tinggi komitmen organisasi karyawan.

Besarnya pengaruh variabel budaya organisasi terhadap komitmen organisasi dapat diketahui dari hasil kuadrat nilai koefisien korelasi sederhananya, yaitu sebesar 0,1608 atau dapat dikatakan bahwa $16,08 \%$ perubahan komitmen organisasi ditentukan atau dipengaruhi oleh budaya organisasi dan sisanya $83,92 \%$ ditentukan oleh faktor lain.

Dari hasil yang telah didapatkan, maka dapat

Available at:

http://journal.unj.ac.id/unj/index.php/econosains/article/view/656 
diinterpretasikan bahwa hubungan antara budaya organisasi dengan komitmen organisasi memiliki hubungan yang positif dan signifikan. Selain itu, budaya organisasi juga memiliki kontribusi dalam meningkatkan komitmen organisasi karyawan PT. Yodya Karya.

Walaupun penelitian ini telah berhasil menguji hipotesis yang diajukan, namun peneliti menyadari bahwa penelitian ini tidak sepenuhnya pada tingkat kebenaran mutlak. Ada beberapa hal yang menjadi hambatan dan kekurangan dalam melakukan penelitian ini adalah sebagai berikut:

1. Kesibukan karyawan di tempat penelitian yang menyebabkan waktu pengembalian pengisian kuesioner terlalu lama sehingga menghambat peneliti dalam mengolah data.

2. Instrumen penelitian sebagai alat pengumpulan data belum dapat mengungkap keseluruhan aspek yang diteliti karena jawaban dari responden hanya terbatas dari kisi-kisi soal yang disebar oleh peneliti.

3. Masih banyak faktor yang dapat mempengaruhi komitmen organisasi, namun faktor yang diteliti pada penelitian ini hanya terbatas pada budaya organisas saja.

\section{DAFTAR PUSTAKA}

Colquit, J. A. (2011). Organizational Behavior. New York: Mc. Graw-Hill Companies.

Kaswan. (2012). Manajamen Sumber Daya Manusia. Yogyakarta: Graha Ilmu .

Luthans, F. (2006). Perilaku Organisasi. Yogyakarta: Andi Offset.

Rivai, v. d. (2010). Kepemimpinan dan Perilaku Organisasi. Jakarta: Rajawali Pers.

Robbins, S. P. (2009). Management. New Jesey: Pearson Education.

Sopiah. (2008). Perilaku Organisasi. Jakarta: PT. Penerbit Andi.

Sugiyono. (2011). Statistika Untuk Penelitian. Bandung : CV Alfabeta.

Sunyoto, D. (2012). Manajamen Sumber Daya Manusia. Jakarta: PT. Buku Seru.

Sunyoto, D. d. (2011). Perilaku Organisasi. . Yogyakarta: CAPS.

Umam, K. (2012). Budaya Organisasi. Jakarta: Rajawali Pers. 